\title{
Lactobacillus gasseri SBT2055 reduces postprandial and fasting serum non-esterified fatty acid levels in Japanese hypertriacylglycerolemic subjects
}

\author{
Akihiro Ogawa ${ }^{1,2}$, Yukio Kadooka ${ }^{2}$, Ken Kato $^{2}$, Bungo Shirouchi ${ }^{1}$ and Masao Sato ${ }^{1 *}$
}

\begin{abstract}
Background: Lactobacillus gasseri SBT2055 (LG2055) inhibits dietary fat absorption in rats and exerts preventive effects on abdominal adiposity in rats and humans. The present study aimed to evaluate the effects of LG2055 on postprandial serum lipid responses in Japanese subjects with hypertriacylglycerolemia after the intake of oral fat-loading test (OFLT) meals.
\end{abstract}

Methods: We conducted a single-blind, placebo-controlled, within-subject, repeated-measure intervention trial. Twenty subjects initially ingested the fermented milk (FM) without LG2055 for 4 weeks (control FM period), followed by a 4-week washout period, and then consumed FM containing LG2055 for 4 weeks (active FM period). The subjects were asked to consume FM at $200 \mathrm{~g} /$ day. At the end of each 4-week period, an 8-h OFLT was conducted. Blood samples were collected at fasting and every hour for $8 \mathrm{~h}$ after OFLT meal intake. Thereafter, postprandial serum non-esterified fatty acid (NEFA) and triacylglycerol (TAG) levels and fasting blood parameters were measured.

Results: The OFLT showed that the postprandial serum NEFA levels from 120 to 480 min and the postprandial serum TAG level at 120 min in the active FM period were significantly $(P<0.05)$ lower than those in the control FM period. The fasting serum NEFA level in the active FM period significantly $(P<0.001)$ decreased at week 4 from the initial period compared with the control FM period.

Conclusions: The consumption of probiotic LG2055 reduced postprandial and fasting serum NEFA levels, suggesting its possible contribution to the reduction of the risk for obesity and type 2 diabetes mellitus.

Trial registration: UMIN000011605

Keywords: Probiotics, Lactobacillus gasseri SBT2055, Oral fat-loading test, Postprandial lipid response, Fermented milk products, Non-esterified fatty acid, Triacylglycerol

\section{Background}

Lactobacillus gasseri SBT2055 (LG2055), a probiotic lactic acid bacterium that originates from the human intestine $[1,2]$ and has the ability to improve the intestinal environment [3], was demonstrated to diminish lymphatic triacylglycerol (TAG) transport and increase fecal fatty acids excretion, thereby inhibiting intestinal fat absorption [4], and to have anti-obesity effects in rats [4-6], mice [7], and humans [8,9]. In our previous

\footnotetext{
* Correspondence: masaos@agr.kyushu-u.ac.jp

'Laboratory of Nutrition Chemistry, Department of Bioscience and Biotechnology, Faculty of Agriculture, Graduate School of Kyushu University, 6-10-1 Hakozaki, Higashi-ku, Fukuoka 812-8581, Japan

Full list of author information is available at the end of the article
}

clinical study $[8,9]$, Japanese adults with obese tendencies consumed fermented milk containing LG2055 at $200 \mathrm{~g} /$ day for 12 weeks and consequently exhibited significantly reduced visceral fat areas, body weight, body mass index (BMI), and waist and hip circumferences. However, the effects of LG2055 on postprandial lipid metabolism remain to be investigated.

Several possible factors affect postprandial lipid metabolism. Energy intake reduction by suppression of dietary fat absorption is a strategy for the regulation of postprandial lipid metabolism. Orlistat, which is a strong lipase inhibitor [10] approved by the US Food and Drug Administration as a medication for long-term obesity treatment [11], improved postprandial lipid metabolism 
in overweight type 2 diabetic patients via the inhibition of fat absorption [12]. Functional food components were also shown to have a suppressive effect on fat absorption and an anti-obesity effect. For example, mannooligosaccharide (MOS) supplementation reduced fat absorption $[13,14]$, leading to body weight and visceral fat loss after 12 weeks in humans $[15,16]$. The inhibition of dietary fat absorption by MOS was more moderate than that by orlistat; orlistat administration reduced fat absorption by approximately 30\% [17], whereas MOS intake significantly lowered fat utilization by approximately $2 \%$ [14]. However, to our knowledge, no intervention study has been conducted to examine postprandial lipid metabolism using probiotics.

In this study, we examined the effects of the probiotic LG2055 on postprandial serum lipid responses in Japanese subjects with hypertriacylglycerolemia, referring to an oral fat-loading test (OFLT) study of Lopez et al. [18].

\section{Methods}

\section{Subjects}

Twenty adults, whose background characteristics are summarized in Table 1, were enrolled in this study. We recruited adults who had hypertriacylglycerolemia with fasting TAG levels higher than $200 \mathrm{mg} / \mathrm{dl}$ [19] and normal blood fasting glucose levels lower than $110 \mathrm{mg} / \mathrm{dl}$.

\section{Table 1 Baseline characteristics of the study subjects}

\begin{tabular}{|c|c|c|}
\hline Parameters & & \\
\hline Number of subjects & 20 & \\
\hline Male & 15 & \\
\hline Female & 5 & \\
\hline Age (years) & 51.1 & $(6.6)$ \\
\hline Height (cm) & 169.6 & $(10.5)$ \\
\hline \multicolumn{3}{|l|}{ Body weight (kg) } \\
\hline Male & 73.7 & $(10.0)$ \\
\hline Female & 61.3 & $(6.3)$ \\
\hline \multicolumn{3}{|l|}{ BMI $\left(\mathrm{kg} / \mathrm{m}^{2}\right)$} \\
\hline Male & 24.2 & $(2.5)$ \\
\hline Female & 25.5 & $(1.4)$ \\
\hline Systolic blood pressure (mm Hg) & 111.0 & (11) \\
\hline Diastolic blood pressure (mm Hg) & 73.0 & (9) \\
\hline Pulse rate (beats/min) & 69.0 & $(8)$ \\
\hline TAG (mg/dl) & 277.0 & (57) \\
\hline Total cholesterol (mg/dl) & 215.0 & $(41)$ \\
\hline NEFA (mEq/l) & 0.58 & $(0.22)$ \\
\hline Glucose (mg/dl) & 90.0 & (7) \\
\hline Insulin ( $\mu \mathrm{U} / \mathrm{ml})$ & 7.3 & $(2.1)$ \\
\hline
\end{tabular}

Abbreviations: BMI body mass index, TAG triacylglycerol, NEFA non-esterified fatty acid.

The data are expressed as mean (SD) values.
Those who had severe internal organ disorders, including coronary heart disease, renal impairment, hypothyroidism, or liver dysfunction, and hypersensitivity to dairy products were excluded. None of the subjects used tobacco, consumed special health-promoting foods, or took medication known to alter gastric emptying, lipoprotein metabolism, insulin secretion, or insulin activity.

\section{Study design}

This study was performed as a single-blind, placebocontrolled, within-subject, repeated-measure intervention trial. The crossover design was not adopted because it was possible that LG2055 survived in the intestinal tract after the washout period [3]. In a previous study, LG2055 was detected in a fecal sample even 90 days after LG2055 administration was discontinued [3]. Therefore, we set the placebo treatment period before the LG2055 treatment period. This study was conducted according to the guidelines established in the Declaration of Helsinki and the Ethical Guidelines for Epidemiological Research (Ministry of Health, Labour and Welfare of Japan), and all procedures involving human subjects/patients were approved by the institutional review board of Fukuda Clinic (Yodogawa-ku, Osaka, Japan) before initiation of the study. All the subjects provided written informed consent before participation in the study. This study was conducted from November 2011 to February 2012 by a contract research organization, Soiken Inc. (Toyonaka, Osaka, Japan). The clinical trial was registered in the University Hospital Medical Information Network Clinical Trials (No. UMIN000011605).

\section{Preparation of the test fermented milk}

Lactobacillus gasseri SBT2055 (LG2055) was provided in fermented milk (FM). Two types of FM were prepared as previously reported [8], that is, active FM containing LG2055 and control FM lacking LG2055. The active FM was prepared with lactic acid bacteria starter cultures (Streptococcus thermophilus and Lactobacillus delbrueckii spp. bulgaricus) that are commonly used for conventional yogurt production and viable cells of LG2055. A FM mixture consisting of approximately $11 \%$ skim milk powder and a small amount of flavoring, agar, and sucralose as artificial sweetener with a zero-energy value was inoculated with the yogurt starter cultures and LG2055 cells and then cultured at $40^{\circ} \mathrm{C}$ for $3.5-4 \mathrm{~h}$. The viable cell count of LG2055 was approximately $5 \times 10^{10} \mathrm{cfu} / 100 \mathrm{~g}$ of FM on the initial day. The control FM was prepared in the same manner except that LG2055 cells were not added. These FM preparations were equivalent in energy (146.4 kJ), protein (3.7 g), fat (0.1 g), carbohydrate $(4.9 \mathrm{~g})$, and sodium content (41 mg) per $100 \mathrm{~g}$ and were indistinguishable in taste. The test FM preparations were kept in cold storage and delivered weekly. 


\section{Study schedule and protocol}

The subjects initially consumed the control FM for 4 weeks, followed by a 4-week washout period, and then the subjects consumed the active FM for 4 weeks. Initiation of the consumption of either the control or active FM was designated as week 0 (W0). While maintaining their habitual mode of living including diet and exercise, the subjects consumed FM at $200 \mathrm{~g} /$ day as two portions of $100 \mathrm{~g}$ each after breakfast and dinner.

Measurements of body weight, waist circumference, blood pressure, pulse rate, and fasting blood parameters and an interview with a physician were performed at the beginning and end of each 4-week intake period (W0 and W4, respectively). At the end of each 4-week intake period, an 8-h OFLT was performed. Each subject made a daily record of the amount of test FM intake, alcohol consumed, and medicine taken. A detailed dietary record was also made by the subjects for three consecutive days before each time point (W0 and W4). Information regarding subjective symptoms such as headache, nausea, and abdominal pain was collected through an interview with a physician at each time point (W0 and W4).

\section{Oral fat-loading test}

The subjects stayed at the same hotel on the day prior to the OFLT and consumed a dinner with an energy content of approximately $3765.6 \mathrm{~kJ}$ between 19:30 and 20:00 hours, after which the subjects were not allowed to eat and drink anything except water until the beginning of the OFLT. The total energy provided by the OFLT meals was $2468.6 \mathrm{~kJ}$, with a macronutrient profile of $72 \%$ fat, $24 \%$ carbohydrate, and $4 \%$ protein, which was in accordance with the methods of Lopez et al. [18]. The meals consisted of $200 \mathrm{~g}$ of corn cream potage (Nagoya Seiraku Co., Ltd., Nagoya, Japan), 37 g of salt-free butter (Megmilk Snow Brand Co., Ltd., Tokyo, Japan), and $29 \mathrm{~g}$ of meal test C (Saraya Co., Ltd., Osaka, Japan); total amount of fat in the meals was $47.2 \mathrm{~g}$. After a 12-h fasting period, the subjects ingested the OFLT meals and concomitantly consumed the test FM. Blood samples were collected from the median cubital, basilic, or cephalic vein before intake of the OFLT meals (fasting) and each hour after $8 \mathrm{~h}$ of OFLT meal intake.

\section{Blood sample analyses}

The blood samples were centrifuged at $1730 \times g$ for 10 min at $4^{\circ} \mathrm{C}$, and the supernatant was stored at a temperature lower than $-30^{\circ} \mathrm{C}$ until analysis. Postprandial serum NEFA and TAG levels were measured at 0 (fasting), $60,120,180,240,300,360,420$, and $480 \mathrm{~min}$. Other blood parameters were measured at fasting state. Assays of serum NEFA, TAG, total cholesterol, low-density lipoprotein cholesterol, high-density lipoprotein cholesterol, insulin, amylase, total protein, alkaline phosphatase, aspartate aminotransferase, alanine aminotransferase, lactase dehydrogenase, gamma-glutamyl transpeptidase, total bilirubin, plasma glucose, and blood hemoglobin A1c (HbA1c) levels were performed at BML (Bio Medical Laboratories) Inc. (Tokyo, Japan). Serum apolipoprotein B-48 (apo B-48) levels were determined using an ELISA kit (AKHB48J, Shibayagi Co., Ltd., Gunma, Japan), in accordance with the manufacturer's instructions. Briefly, sera diluted 500- or 1000-fold in the assay diluents were added to microtiter wells coated with immobilized anti-apo B-48 monoclonal antibody and incubated at room temperature for $1 \mathrm{~h}$. After washing with a washing buffer, biotin-conjugated anti-apo B-48 was added to each well and incubated with gentle shaking at room temperature for $1 \mathrm{~h}$. After the plate was washed, horseradish peroxidase-conjugated avidin solution was added, and the resultant solution was incubated at room temperature for $30 \mathrm{~min}$. After the plate was washed, chromogenic substrate solution was added, and the resultant solution was incubated at room temperature for $20 \mathrm{~min}$. Finally, a stop solution for the reaction was added, and then the absorbance of $450 \mathrm{~nm}$ at each well was measured using a plate reader.

\section{Statistical analysis}

The baseline characteristics of the subjects were expressed as means with their standard deviations. Other data were expressed as means with their standard errors. The incremental area under the curve (iAUC) for NEFA and TAG were calculated using the trapezoidal rule. Differences in the amount of change between the control and active FM periods were analyzed using a paired $t$ test. Postprandial serum TAG levels were determined by a one-sided test because in our previous study, LG2055 inhibited the absorption of dietary TAG in rats, making it unnecessary to consider lipid absorption enhancement [4]. The statistical differences in the other parameters were analyzed by a two-sided test. We considered a $P<0.05$ to be statistically significant.

\section{Results}

\section{Effects of the active FM on the postprandial NEFA and TAG levels}

All the participants followed the study protocol without difficulty. The postprandial responses of serum NEFA level after the intake of the OFLT meals are shown in Figure 1a. The serum NEFA levels showed a temporary downturn from the baseline and then turned upward. Active FM significantly decreased the postprandial serum NEFA levels from 120 to $480 \mathrm{~min}$ after the intake of the OFLT meals compared with the control FM (from 120 to $240 \mathrm{~min}$, $P<0.05$; from 300 to $480 \mathrm{~min}, P<0.01$ ), leading to a significantly lower NEFA-iAUC $(P<0.01)$. There was no significant difference in NEFA-iAUC between males and females 


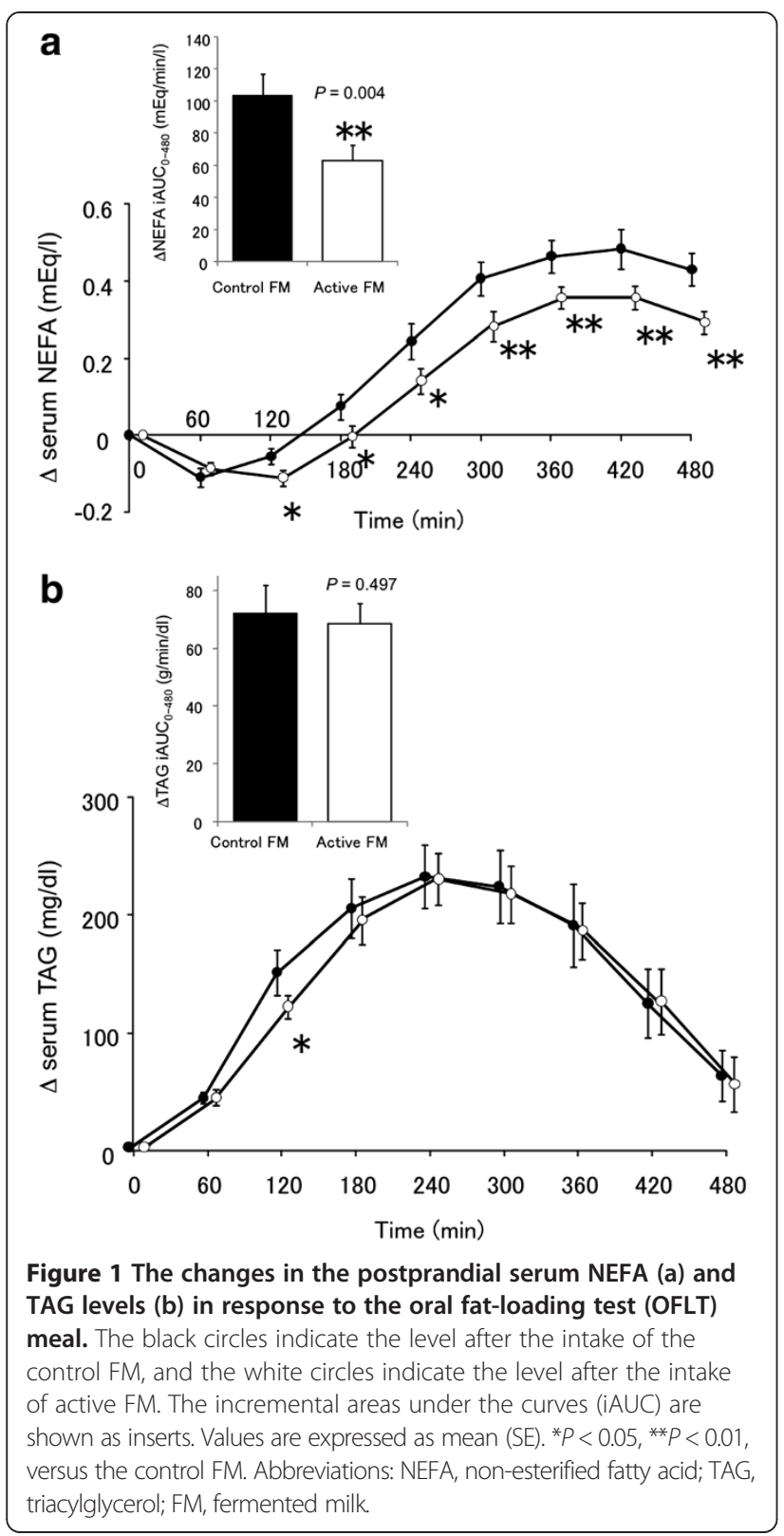

$(99.4 \pm 16.2 \mathrm{mEq} / \mathrm{min} / \mathrm{l}$ and $115.6 \pm 23.3 \mathrm{mEq} / \mathrm{min} / \mathrm{l}$ in the control FM period, respectively; $61.4 \pm 12.1 \mathrm{mEq} / \mathrm{min} / \mathrm{l}$ and $75.8 \pm 13.2 \mathrm{mEq} / \mathrm{min} / \mathrm{l}$ in the active $\mathrm{FM}$ period, respectively).

The postprandial responses of the serum TAGs are illustrated in Figure 1b. When the subjects consumed the OFLT meal, the serum TAG levels quickly increased from the baseline $(0 \mathrm{~min})$ and reached their highest levels at $240 \mathrm{~min}$ after the OFLT meal intake. In the active FM period, the serum TAG level at 120 min after the intake of the OFLT meals was significantly lower $(P<0.05)$ than that in the control FM period. No significant difference in TAG-iAUC was found between the periods.
Effects of the active FM on the anthropometric and fasting blood parameters

The effects of the control and active FM preparations on the anthropometric and fasting blood parameters are listed in Table 2. None of the anthropometric parameters showed statistically significant differences in changes from W0 between the control and active FM periods. Among the blood parameters, the value of change from WO in fasting serum NEFA level in the active FM period significantly decreased $(P<0.001)$ compared with that in the control FM period. There was no significant difference in the value of change from WO in fasting NEFA level between males and females $(0.09 \pm 0.05 \mathrm{mEq} / \mathrm{l}$ and $0.10 \pm$ $0.07 \mathrm{mEq} / \mathrm{l}$ in the control FM period, respectively; $-0.06 \pm$ $0.04 \mathrm{mEq} / \mathrm{l}$ and $-0.04 \pm 0.01 \mathrm{mEq} / \mathrm{l}$ in the active $\mathrm{FM}$ period, respectively). A significant difference $(P=0.002)$ in the value of change from W0 in HbA1c level was observed between the control and active FM periods, in which the value was greater in the active period than in the control period (Table 2), although these real values were lower than $6.5 \%$ of the cutoff $\mathrm{HbA} 1 \mathrm{c}$ level for diabetes diagnosis as recommended by the World Health Organization [20]. No significant differences in the other fasting serum parameters were found between the control and active FM periods.

\section{Daily life and adverse events}

Irregularities in daily life or adverse events related to FM consumption were not observed throughout the course of the study, according to the daily record and interview with the physician (data not shown).

\section{Discussion}

We investigated the postprandial lipid responses after an OFLT meal intake in the subjects with hypertriacylglycerolemia who ingested fermented milk with or without LG2055 for 4 weeks. To our knowledge, this is the first intervention study on OFLT in probiotics. The postprandial serum NEFA levels from 120 to 480 min after OFLT meal intake in the active FM period were significantly lower than those in the control FM period (Figure 1a). The postprandial serum TAG levels in the active FM period tended to be lower from 60 to $180 \mathrm{~min}$ and significantly lower at $120 \mathrm{~min}$ compared with the control FM period (Figure 1b). This time point of $120 \mathrm{~min}$ corresponded to the time point when the postprandial NEFA levels in the active FM period were still prevented from increasing, whereas in the control FM period, the NEFA levels already began to increase from the time point of $60 \mathrm{~min}$. We consider that this delayed onset of the increase in the NEFA level in the active FM period might lead to the subsequent lowered NEFA levels in the active FM period compared with the control FM period. Furthermore, the plateau level of the postprandial NEFA 
Table 2 Anthropometric parameters and fasting levels of the blood parameters before and after the intake of control or active FM

\begin{tabular}{|c|c|c|c|c|c|c|c|c|}
\hline \multirow{2}{*}{\multicolumn{2}{|c|}{$\begin{array}{l}\text { Parameters Period } \\
\text { Anthropometric parameters }\end{array}$}} & \multicolumn{2}{|c|}{ wo } & \multicolumn{2}{|c|}{ W4 } & \multicolumn{2}{|c|}{ Change from W0 } & \multirow[t]{2}{*}{$P$ value } \\
\hline & & & & & & & & \\
\hline Body weight & Control & 70.5 & $(2.4)$ & 70.3 & $(2.4)$ & -0.23 & $(0.26)$ & 0.093 \\
\hline (kg) & Active & 70.7 & $(2.4)$ & 70.6 & (2.3) & -0.04 & $(0.12)$ & \\
\hline BMI & Control & 24.5 & $(0.5)$ & 24.4 & $(0.5)$ & -0.09 & $(0.09)$ & 0.512 \\
\hline$\left(\mathrm{kg} / \mathrm{m}^{2}\right)$ & Active & 24.5 & $(0.5)$ & 24.5 & $(0.5)$ & -0.01 & $(0.04)$ & \\
\hline Waist & Control & 87.4 & $(1.5)$ & 85.6 & (1.3) & -1.78 & $(0.53)$ & 0.461 \\
\hline$(\mathrm{cm})$ & Active & 85.4 & $(1.5)$ & 84.7 & (1.4) & -0.75 & $(0.35)$ & \\
\hline \multicolumn{9}{|l|}{ Blood parameters } \\
\hline TAG & Control & 246.5 & $(18.9)$ & 272.4 & $(26.9)$ & 25.9 & $(24.9)$ & 0.528 \\
\hline$(\mathrm{mg} / \mathrm{dl})$ & Active & 268.3 & (31.5) & 273.4 & $(33.5)$ & 5.2 & $(14.4)$ & \\
\hline NEFA & Control & 0.382 & $(0.033)$ & 0.472 & $(0.034)$ & 0.090 & $(0.037)$ & 0.0003 \\
\hline$(\mathrm{mEq} / \mathrm{l})$ & Active & 0.399 & $(0.031)$ & 0.344 & $(0.026)$ & -0.056 & $(0.026)$ & \\
\hline Apo B-48 & Control & 9.38 & $(1.44)$ & 9.98 & $(1.31)$ & 0.59 & $(0.76)$ & 0.173 \\
\hline$(\mu \mathrm{g} / \mathrm{ml})$ & Active & 10.24 & $(2.06)$ & 9.25 & $(1.46)$ & -0.98 & $(0.89)$ & \\
\hline Total cholesterol & Control & 215.7 & $(9.1)$ & 220.5 & (8.6) & 4.8 & (4.3) & 0.797 \\
\hline$(\mathrm{mg} / \mathrm{dl})$ & Active & 214.1 & $(7.0)$ & 217.2 & $(7.8)$ & 3.1 & $(4.4)$ & \\
\hline LDL cholesterol & Control & 128.7 & $(8.3)$ & 132.5 & (7.1) & 3.8 & $(4.0)$ & 0.347 \\
\hline$(\mathrm{mg} / \mathrm{dl})$ & Active & 127.0 & $(7.0)$ & 125.0 & $(7.3)$ & -2.0 & (3.4) & \\
\hline HDL cholesterol & Control & 43.5 & $(2.0)$ & 43.4 & (2.1) & -0.2 & $(0.8)$ & 0.504 \\
\hline$(\mathrm{mg} / \mathrm{dl})$ & Active & 43.6 & $(2.4)$ & 42.4 & (2.2) & -1.2 & $(1.2)$ & \\
\hline Glucose & Control & 94.5 & $(2.0)$ & 94.1 & $(2.0)$ & -0.4 & $(1.0)$ & 0.883 \\
\hline$(\mathrm{mg} / \mathrm{dl})$ & Active & 93.4 & $(2.6)$ & 93.4 & $(2.0)$ & 0.0 & (1.9) & \\
\hline Insulin & Control & 9.01 & $(0.66)$ & 8.60 & $(0.85)$ & -0.41 & $(0.46)$ & 0.998 \\
\hline$(\mu \mathrm{U} / \mathrm{ml})$ & Active & 10.63 & (2.39) & 10.22 & $(0.95)$ & -0.41 & (2.45) & \\
\hline Amylase & Control & 81.5 & $(8.3)$ & 94.3 & $(21.1)$ & 12.8 & $(14.5)$ & 0.217 \\
\hline$(\mathrm{U} / \mathrm{l})$ & Active & 103.5 & (21.4) & 91.5 & $(15.3)$ & -12.0 & (8.6) & \\
\hline $\mathrm{HbA1c}$ & Control & 5.04 & $(0.04)$ & 5.01 & $(0.05)$ & -0.03 & $(0.03)$ & 0.002 \\
\hline (\%) & Active & 5.05 & $(0.05)$ & 5.13 & $(0.05)$ & 0.08 & $(0.01)$ & \\
\hline Total protein & Control & 7.05 & $(0.07)$ & 7.14 & $(0.06)$ & 0.09 & $(0.05)$ & 0.192 \\
\hline$(g / d l)$ & Active & 6.99 & $(0.07)$ & 7.00 & $(0.07)$ & 0.01 & $(0.04)$ & \\
\hline ALP & Control & 215.9 & $(13.0)$ & 219.3 & $(13.5)$ & 3.4 & $(4.6)$ & 0.421 \\
\hline$(\mathrm{U} / \mathrm{l})$ & Active & 209.3 & (12.3) & 227.5 & (20.8) & 18.2 & $(16.2)$ & \\
\hline AST & Control & 20.8 & $(1.2)$ & 20.7 & $(1.2)$ & -0.1 & $(0.8)$ & 0.974 \\
\hline$(\mathrm{U} / \mathrm{l})$ & Active & 21.0 & $(1.2)$ & 21.0 & $(1.1)$ & 0.0 & $(0.9)$ & \\
\hline ALT & Control & 24.8 & $(1.8)$ & 24.2 & $(2.3)$ & -0.6 & $(1.7)$ & 0.674 \\
\hline$(\mathrm{U} / \mathrm{I})$ & Active & 23.2 & $(2.1)$ & 23.9 & (1.9) & 0.7 & $(1.7)$ & \\
\hline LDH & Control & 159.9 & (3.4) & 159.3 & (3.0) & -0.6 & (1.8) & 0.055 \\
\hline$(\mathrm{U} / \mathrm{l})$ & Active & 154.4 & $(2.9)$ & 161.2 & $(4.2)$ & 6.8 & (2.6) & \\
\hline$\gamma$-GTP & Control & 49.2 & $(7.5)$ & 52.8 & $(7.0)$ & 3.7 & (3.0) & 0.484 \\
\hline$(\mathrm{U} / \mathrm{l})$ & Active & 48.3 & $(7.1)$ & 61.6 & $(17.3)$ & 13.4 & $(12.3)$ & \\
\hline Total bilirubin & Control & 0.82 & $(0.09)$ & 0.81 & $(0.06)$ & -0.01 & $(0.06)$ & 0.088 \\
\hline$(\mathrm{mg} / \mathrm{dl})$ & Active & 0.88 & $(0.06)$ & 0.71 & $(0.06)$ & -0.18 & $(0.04)$ & \\
\hline
\end{tabular}

Abbreviations: TAG triacylglycerol, NEFA non-esterified fatty acid, Apo apolipoprotein, LDL low-density lipoprotein, HDL high-density lipoprotein, HbA1c hemoglobin A1c, ALP alkaline phosphatase, AST aspartate aminotransferase, ALT alanine aminotransferase, $L D H$ lactase dehydrogenase, $\gamma$-GTP gamma-glutamyl transpeptidase. The data are expressed as mean (SE) at each time point before (week 0, W0) and after (week 4, W4) intake of control or active FM $(n=20)$. A paired $t$ test was performed to compare the changes in the response to the control and active FM. 
that was attained in the active FM period at approximately 360 min was significantly lower than that in the control FM period at around the same time point; thus, we also consider that the lower NEFA levels reflected the inhibited increase in the TAG levels, which are primarily influenced by the state of fat absorption.

Tan et al. [12] also reported that postprandial NEFA levels from 120 to $240 \mathrm{~min}$ and postprandial TAG level at $120 \mathrm{~min}$ after OFLT meal intake in diabetes subjects treated with orlistat were significantly decreased compared with those in subjects treated with a placebo. They described that the decreased NEFA levels were generated from the event that NEFA was not supplied from the postprandial TAG owing to the suppression of fat absorption. This finding is consistent with our results and suggests that the suppression of lipid absorption by LG2055 may contribute to the significantly decreased NEFA levels in this postprandial period. Inhibition of pancreatic lipase can possibly suppress lipid absorption, as it has recently been reported that two Lactobacilli strains, viable Lactobacillus gasseri NLB367 [21] and heat-killed Lactobacillus pentosus S-PT84 [22], inhibited pancreatic lipase in vitro, although whether our LG2055 strain inhibits lipase activity has yet to be examined.

The postprandial serum NEFA levels after $240 \mathrm{~min}$ (the late postprandial phase) in the active FM period were significantly lower than those in the control FM period, although the postprandial TAG levels during the time did not differ between the control and active FM periods. NEFA is known to be produced from the TAG hydrolysis process by lipoprotein lipase to produce NEFA and glycerol, which are incorporated into the liver, muscles, and adipose tissues. In the present study, TAG was likely to be equally hydrolyzed to generate the same amount of NEFA, given that TAG levels did not differ between the control and active FM periods after $240 \mathrm{~min}$. However, difference in the ability to incorporate NEFA could cause the different NEFA levels between the control and active FM periods; thus we consider that the control FM period might less incorporate NEFA than the active FM period. Such NEFA which is not incorporated and remaining in the bloodstream is known to be crucial for the late postprandial rise in NEFA [23,24].

Ingestion of the anti-diabetic drug rosiglitazone, known as a peroxisome proliferator-activated receptor (PPAR)- $\gamma$ agonist, was reported to significantly lower plasma NEFA levels during the postprandial period and simultaneously reduce plasma TAG levels from 240 to $360 \mathrm{~min}$ [25]. However, LG2055 did not affect serum TAG levels from 240 to $480 \mathrm{~min}$ (Figure 1b). Rosiglitazone ameliorates blood glucose levels in diabetic subjects via the incorporation of some amount of blood glucose into the adipose tissues, along with some amount of blood NEFA derived from the TAG hydrolysate; this mechanism occasionally leads to adverse effects such as increases in body fat mass and body weight $[26,27]$. By contrast, while LG2055 ingestion decreased body fat mass and body weight in humans $[8,9]$, postprandial NEFA levels were also significantly lowered by LG2055 ingestion. Thus, the effects of LG2055 on lipid metabolism may differ from those of the PPAR- $\gamma$ agonist.

Judging from the unchanged TAG-iAUC result, we consider the magnitude of the fat absorption suppression by LG2055 to be mild (Figure 1b). The mild suppression may be due to the experimental condition we applied in the present study. Although there are no official guidelines for the OFLT, recent studies performed OFLT using a moderate $(0.35-0.7 \mathrm{~g}$ of fat $/ \mathrm{kg}$ body mass) rather than a high-fat meal [28], and our study has also been carried out within the moderate range $(0.67 \mathrm{~g}$ of $/ \mathrm{kg}$ body mass). In addition to the amount of fat loading, other factors such as racial differences greatly affect the postprandial TAG response [29]. Therefore, we compared the experimental condition of our study with that of other studies, in which Japanese subjects were recruited and the effects of functional food components on the postprandial TAG levels were examined [30-32]. The amount of fat loading was higher, and the high baseline fasting serum TAG levels of our subjects, in comparison with those of other studies. Other studies performed an OFLT and evaluated the suppressive effects of functional food components [30-32] at loading levels of 18.8 to $40 \mathrm{~g}$ of fat, whereas our study was performed at a loading level of $47.2 \mathrm{~g}$ of fat. In addition, the baseline fasting serum TAG levels of the subjects in the other studies ranged from 144.5 to $175 \mathrm{mg} / \mathrm{dl}$, whereas the mean baseline level in our study was $277.0 \mathrm{mg} / \mathrm{dl}$. These factors might lead to higher increases in TAG after OFLT; the $\triangle$ TAG level was 231.2 $\mathrm{mg} / \mathrm{dl}$ in our study, whereas it ranged from 61 to 130 $\mathrm{mg} / \mathrm{dl}$ in the other reports. Thus, the great increase in postprandial TAG levels in our study might have obscured the suppressive effect of LG2055 on postprandial TAG responses.

An elevation of blood TAG levels is a well recognized cardiovascular risk factor [33]. We consider that lowering NEFA levels is also beneficial for human health as well as lowering TAG levels. Elevated NEFA levels are a predictor of subsequent development of type 2 diabetes [34], and associated with the deterioration of glucose tolerance $[35,36]$. Dysregulation of plasma NEFA levels is central to the insulin resistance and is associated with dyslipidemia [37]. In the present study, a significant decrease in fasting NEFA level at W4 from W0 was observed in the active FM period (Table 2), which could be a possible accumulated effect of the decrease in the postprandial NEFA levels (Figure 1a) over time. The ability of LG2055 to continuously lower serum NEFA levels may help reduce the risk for T2DM and obesity. 
Though physiologically normal, a significant difference in the value of change from W0 in HbA1c level was observed between the active and control FM periods, in which the value was greater in the active FM period than in the control FM period (Table 2). Additionally, withinperiod comparisons between W0 and W4 did not reveal significant differences both in the control and in the active FM periods (statistical symbols were not shown). This observation is consistent with that reported by Chang et al. [38]. They reported that blood HbA1c levels tended to increase in healthy volunteers who consumed a probiotic yogurt NY-YP901 for 8 weeks, whereas the intake of placebo yogurt for 8 weeks tended to decrease blood HbA1c levels.

\section{Conclusions}

In conclusion, the consumption of probiotic LG2055 reduced postprandial serum NEFA levels after the intake of OFLT meals and fasting NEFA levels at the end of the feeding period, suggesting its possible contribution to the reduction of the risk for obesity and T2DM.

\section{Abbreviations}

LG2055: Lactobacillus gasseri SBT2055; OFLT: Oral fat-loading test; FM: Fermented milk; NEFA: Non-esterified fatty acid; TAG: Triacylglycerol; BMl: Body mass index; MOS: Mannooligosaccharide; HbA1c: hemoglobin A1c; apo B-48: Apolipoprotein B-48; iAUC: Incremental area under the curve.

\section{Competing interests}

The authors declare that they have no competing interest.

\section{Authors' contributions}

$\mathrm{AO}$ and $\mathrm{BS}$ wrote the manuscript. YK assisted with the data analysis and interpretation. KK was responsible for the study. MS supervised the study design and commented on the paper. All authors read and approved the final manuscript.

\section{Acknowledgments}

We thank the participants for their cooperation, as well as Professor Osami Kajimoto of Osaka City University, Mr Tomohiro Sugino of Soiken Inc., Dr Masahiro Fukuda of the Fukuda Clinic, and the staff members of the respective facilities.

\section{Author details}

${ }^{1}$ Laboratory of Nutrition Chemistry, Department of Bioscience and Biotechnology, Faculty of Agriculture, Graduate School of Kyushu University, 6-10-1 Hakozaki, Higashi-ku, Fukuoka 812-8581, Japan. ${ }^{2}$ Milk Science Research Institute, Megmilk Snow Brand Co. Ltd., 1-1-2 Minamidai, Kawagoe, Saitama 350-1165, Japan.

Received: 2 December 2013 Accepted: 5 February 2014 Published: 19 February 2014

\section{References}

1. Seto Y, Kimura A, Akai Y, Fujiwara S: Distribution of the Lactobacillus acidophilus complex in human fecal specimens examined by restriction fragment length polymorphism of the 16S rRNA genes. Biosci Microflora 2003, 22:75-83.

2. Takahashi H, Fujita T, Suzuki Y, Benno Y: Monitoring and survival of Lactobacillus gasseri SBT2055 in the human intestinal tract. Microbiol Immunol 2006, 50:867-870.

3. Fujiwara S, Seto Y, Kimura A, Hashiba H: Establishment of orally-administered Lactobacillus gasseri SBT2055SR in the gastrointestinal tract of humans and its influence on intestinal microflora and metabolism. J App/ Microbio/ 2001, 90:343-352
4. Hamad EM, Sato M, Uzu K, Yoshida T, Higashi S, Kawakami H, Kadooka Y, Matsuyama H, Abd El-Gawad IA, Imaizumi K: Milk fermented by Lactobacillus gasseri SBT2055 influences adipocyte size via inhibition of dietary fat absorption in Zucker rats. Br J Nutr 2009, 101:716-724.

5. Sato M, Uzu K, Yoshida T, Hamad EM, Kawakami H, Matsuyama H, Abd El-Gawad IA, Imaizumi K: Effects of milk fermented by Lactobacillus gasseri SBT2055 on adipocyte size in rats. Br J Nutr 2008, 99:1013-1017.

6. Kadooka Y, Ogawa A, Ikuyama K, Sato M: The probiotic Lactobacillus gasseri SBT2055 inhibits enlargement of visceral adipocytes and upregulation of serum soluble adhesion molecule (sICAM-1) in rats. Int Dairy J 2011, 21:623-627.

7. Miyoshi M, Ogawa A, Higurashi S, Kadooka Y: Anti-obesity effect of Lactobacillus gasseri SBT2055 accompanied by inhibition of pro-inflammatory gene expression in the visceral adipose tissue in diet-induced obese mice. Eur J Nutr 2013. e-pub ahead of print 6 August 2013; doi:10.1007/s00394-013-0568-9.

8. Kadooka Y, Sato M, Imaizumi K, Ogawa A, Ikuyama K, Akai Y, Okano M, Kagoshima M, Tsuchida T: Regulation of abdominal adiposity by probiotics (Lactobacillus gasseri SBT2055) in adults with obese tendencies in a randomized controlled trial. Eur J Clin Nutr 2010, 64:636-643.

9. Kadooka Y, Sato M, Ogawa A, Miyoshi M, Uenishi H, Ogawa H, Ikuyama K, Kagoshima M, Tsuchida T: Effect of Lactobacillus gasseri SBT2055 in fermented milk on abdominal adiposity in adults in a randomized controlled trial. Br J Nutr 2013, 110:1696-1703.

10. Carrière F, Renou C, Ransac S, Lopez V, De Caro J, Ferrato F, De Caro A Fleury A, Sanwald-Ducray P, Lengsfeld H, Beglinger C, Hadvary P, Verger R, Laugier R: Inhibition of gastrointestinal lipolysis by orlistat during digestion of test meals in healthy volunteers. Am J Physiol Gastrointest Liver Physiol 2001, 281:G16-G28.

11. U.S. Food and Drug Administration (fda): Orlistat (Marketed As Alli And Xenical) Information. http://www.fda.gov/Drugs/DrugSafety/Postmarket DrugSafetyInformationforPatientsandProviders/ucm180076.htm] (accessed November 29, 2013.

12. Tan KC, Tso AW, Tam SC, Pang RW, Lam KS: Acute effect of orlistat on postprandial lipaemia and free fatty acids in overweight patients with type 2 diabetes mellitus. Diabet Med 2002, 19:944-948.

13. Kumao T, Fujii S: Mannooligosaccharides blended coffee beverage intake increases the fat level in feces. J Health Sci 2006, 52:329-332.

14. Kumao T, Fujii S, Asakawa A, Takehara I, Fukuhara I: Effect of coffee drink containing mannooligosaccharides on total amount of excreted fat in healthy adults. J Health Sci 2006, 52:482-485.

15. Asano I, Fujii S, Ozaki K, Takahara I, Yano Y, Fukuhara I: Effects of "coffee beverage" containing mannooligosaccharides from coffee on human abdominal fat by long term ingestion. Jpn J Food Eng 2005, 6:133-141.

16. Asano I, Fujii S, Kaneko M, Takehara I, Fukuhara I: Investigation of mannooligosaccharides blended coffee beverage on abdominal fat reduction in human. Jap J Med Pharm Sci 2006, 55:93-103.

17. Guericiolini R: Mode of action of orlistat. Int J Obes Relat Metab Disord 1997, 21:S12-S23.

18. Lopez S, Bermudez B, Ortega A, Varela LM, Pacheco YM, Villar J, Abia R, Muriana FJ: Effects of meals rich in either monounsaturated or saturated fat on lipid concentrations and on insulin secretion and action in subjects with high fasting triglyceride concentrations. Am J Clin Nutr 2011, 93:494-499.

19. National Cholesterol Education Program (NCEP) Expert Panel on Detection, Evaluation, and Treatment of High Blood Cholesterol in Adults (Adult Treatment Panel III): Third report of the National Cholesterol Education Panel (NCEP) Expert Panel on Detection, Evaluation, and Treatment of High Blood Cholesterol in Adults (Adult Treatment Panel III) final report. Circulation 2002, 106:3143-3421.

20. Report of a World Health Organization Consultation: Use of glycated haemoglobin ( $\mathrm{HbA1c}$ ) in the diagnosis of diabetes mellitus. Diabetes Res Clin Pract 2011, 93:299-309.

21. Matsumura $A$ : Inhibitory effects of probiotics on pancreatic lipase [in Japanese]. J Intest Microbiol 2010, 24:287-292.

22. Zhou Y, Inoue N, Ozawa R, Maekawa T, Izumo T, Kitagawa Y, Kiso Y, Shibata $H$, Ikeda I: Effects of heat-killed Lactobacillus pentosus S-PT84 on postprandial hypertriacylglycerolemia in rats. Biosci Biotechnol Biochem 2013, 77:591-594.

23. Lambert JE, Parks EJ: Postprandial metabolism of meal triglyceride in humans. Biochim Biophys Acta 1821, 2012:721-726. 
24. Frayn KN, Coppack SW, Fielding BA, Humphreys SM: Coordinated regulation of hormone-sensitive lipase and lipoprotein lipase in human adipose tissue in vivo: implications for the control of fat storage and fat mobilization. Adv Enzyme Regul 1995, 35:163-178.

25. Tan GD, Fielding BA, Currie JM, Humphreys SM, Désage M, Frayn KN, Laville $M$, Vidal H, Karpe F: The effects of rosiglitazone on fatty acid and triglyceride metabolism in type 2 diabetes. Diabetologia 2005, 48:83-95.

26. Wagstaff AJ, Goa KL: Rosiglitazone: a review of its use in the management of type 2 diabetes mellitus. Drugs 2002, 62:1805-1837.

27. Kim SK, Hur KY, Kim HJ, Shim WS, Ahn CW, Park SW, Cho YW, Lim SK, Lee HC, Cha BS: The increase in abdominal subcutaneous fat depot is an independent factor to determine the glycemic control after rosiglitazone treatment. Eur J Endocrinol 2007, 157:167-174.

28. Maraki MI, Sidossis LS: The latest on the effect of prior exercise on postprandial lipaemia. Sports Med 2013, 43:463-481.

29. Friday KE, Srinivasan SR, Elkasabany A, Dong C, Wattigney WA, Dalferes E Jr. Berenson GS: Black-white differences in postprandial triglyceride response and postheparin lipoprotein lipase and hepatic triglyceride lipase among young men. Metabolism 1999, 48:749-754.

30. Hara Y, Moriguchi S, Kusumoto A, Nakai M, Ono Y, Abe K, Ohta H, Shibata H, Kiso Y, Egawa K: Suppressive effect of oolong tea polymerized polyphenols-enriched oolong tea on postprandial serum triglyceride elevation [in Japanese]. Jpn Pharmacol Ther 2004, 32:335-342.

31. Unno T, Tago M, Suzuki Y, Nozawa A, Sagesaka YM, Kakuda T, Egawa K, Kondo $\mathrm{K}$ : Effect of tea catechins on postprandial plasma lipid responses in human subjects. Br J Nutr 2005, 93:543-547.

32. Sugiyama H, Akazome Y, Shoji T, Yamaguchi A, Yasue M, Kanda T, Ohtake Y: Oligomeric procyanidins in apple polyphenol are main active components for inhibition of pancreatic lipase and triglyceride absorption. J Agric Food Chem 2007, 55:4604-4609.

33. Hokanson JE, Austin MA: Plasma triglyceride level is a risk factor for cardiovascular disease independent of high-density lipoprotein cholesterol level: a meta-analysis of population-based prospective studies. I Cardiovasc Risk 1996, 3:213-219.

34. Paolisso G, Tataranni PA, Foley JE, Bogardus C, Howard BV, Ravussin E: A high concentration of fasting plasma non-esterified fatty acids is a risk factor for the development of NIDDM. Diabetologia 1995, 38:1213-1217.

35. Boden G, Cheung P, Stein TP, Kresge K, Mozzoli M: FFA cause hepatic insulin resistance by inhibiting insulin suppression of glycogenolysis. Am J Physiol Endocrinol Metab 2002, 283:E12-E19.

36. Charles MA, Eschwège E, Thibult N, Claude JR, Warnet JM, Rosselin GE, Girard J, Balkau B: The role of non-esterified fatty acids in the deterioration of glucose tolerance in Caucasian subjects: results of the Paris Prospective Study. Diabetologia 1997, 40:1101-1106.

37. Frayn KN, Williams CM, Arner P: Are increased plasma non-esterified fatty acid concentrations a risk marker for coronary heart disease and other chronic diseases? Clin Sci 1996, 90:243-253.

38. Chang BJ, Park SU, Jang YS, Ko SH, Joo NM, Kim SI, Kim CH, Chang DK Effect of functional yogurt NY-YP901 in improving the trait of metabolic syndrome. Eur J Clin Nutr 2011, 65:1250-1255.

doi:10.1186/1476-511X-13-36

Cite this article as: Ogawa et al: Lactobacillus gasseri SBT2055 reduces postprandial and fasting serum non-esterified fatty acid levels in Japanese hypertriacylglycerolemic subjects. Lipids in Health and Disease 2014 13:36.

\section{Submit your next manuscript to BioMed Central and take full advantage of:}

- Convenient online submission

- Thorough peer review

- No space constraints or color figure charges

- Immediate publication on acceptance

- Inclusion in PubMed, CAS, Scopus and Google Scholar

- Research which is freely available for redistribution

Submit your manuscript at www.biomedcentral.com/submit
Ciomed Central 